\title{
Unintended Pregnancy and Induced Abortion in the Netherlands 1954-2002
}

\author{
Mark Levels, Ariana Need, Rense Nieuwenhuis, Roderick Sluiter and \\ Wout Ultee
}

In the Netherlands, abortion is legal, safe, easily available, and free of charge.

Paradoxically, it is also extremely rare. Little quantitative research into the Netherlands' abortion practice has been done. We analyse the fertile life-course of $N=3,793$ Dutch women between 1954 and 2002. Using repeated event history analyses and sequential logistic regression, we test hypotheses on individual and societal effects on women's likelihood of experiencing (unintended) pregnancies and abortions during their life-course. The most important findings pertain to the effect of policies and laws intended to regulate reproductive behaviour. During the observation period, permissive abortion legislation and higher availability of abortion services increased the likelihood that Dutch women terminated unintended pregnancies. Abortion insurance did not affect the likelihood that women terminated an unintended pregnancy. Results suggest that the legalization, availability, and insurance of contraceptive pills helped to prevent abortions, because these measures effectively reduced the demand for abortion.

\section{Introduction}

Social-scientific literature about abortion commonly focuses on explaining macro-level differences in aggregate abortion outcomes. For example, researchers compare the level of access to abortion services in various US states with their respective abortion rates (Gober, 1997; Gius, 2007), or cross-nationally compare abortion rates (Sedgh et al., 2007). This body of research is descriptively elucidative in the sense that it has revealed societal effects (e.g. the legal context, the extent to which safe abortion services are accessible or the availability of contraceptives) that are plausibly connectable to individuals' abortion decisions and, by aggregate, to macro-level differences in abortion outcomes. However, existing literature cannot provide a sufficiently informative theoretical explanation of macro-level differences in aggregate abortion outcomes. Studies that aim to explain aggregate reproductive and abortion outcomes usually explicitly or implicitly assume that women (and sometimes their partners) evaluate the costs and benefits when making reproductive decisions, and act accordingly (cf. Levine, 2004). Although explananda involve macro-level phenomena, explanatory theoretical arguments are built on hypotheses about individuals' behaviour. However, hypotheses about individuals' behaviour cannot be tested by studying macro-level correlates without running the risk of ecological fallacies. To rigorously test the viability of theoretical claims about the effect of individual-level and societal characteristics on abortion outcomes, hypotheses on factors influencing individuals' behaviour must be tested at the individual level. Otherwise, 
the bases for accepting or rejecting hypotheses remain ambiguous.

In this article, we test hypotheses about the determinants of abortion outcomes of women in the Netherlands between 1954 and 2002. The Netherlands were among the first Western countries to legalize abortion in 1984. Furthermore, safe abortion services have been readily accessible since 1971, when the first specialized abortion clinic opened, and abortion procedures have been fully covered by collective health insurance as of 1985. Dutch women who sought to terminate an unintended pregnancy during the past three decades have not faced any serious constraints. The rationality assumption stipulates that with the progressive lifting of constraints between 1970 and the 1980s, the incidence of abortion should gradually increase. As Figure 1 suggests, this predicted increase has indeed been observed (Wijsen, Van Lee and Koolstra, 2007). However, theory also predicts that a relatively low number of serious constraints would lead to a relatively high abortion incidence. In comparison with countries that have more and more serious legal constraints, the Netherlands should have a relatively high abortion incidence. This prediction is repeatedly refuted by empirical findings. Paradoxically, abortion has been a relatively rare phenomenon in the Netherlands for nearly three decades (Sedgh et al., 2007). This apparent challenge to theoretical predictions makes the Netherlands a particularly interesting case to study. The few available studies about abortion in the Netherlands are descriptive, qualitative or aimed at explaining macro-level outcomes. This literature suggests multiple explanations for the Dutch paradox. First, it is argued that the relatively rare incidence of abortion in the Netherlands is explained by the composition of the Dutch population. Compositional explanations include the relatively high general education level or the relatively low numbers of immigrants. Also, scholars argue that specific societal characteristics partially explain the low abortion incidence. Descriptive studies point to the good availability of modern contraceptives and high accessibility of family planning services (Ketting and Schnabel, 1980; Ketting and Visser, 1994; Wijsen, Van Lee and Koolstra, 2007). However, no rigorous quantitative analyses of the merits of these explanations have yet been done. In this article, we provide such analyses.

We add to existing literature in three ways. First, by analytically focusing on individuals' behaviour we claim to provide a better insight in the way individual and societal properties can affect abortion outcomes. We use a theory about individuals' behaviour as a foundation for hypotheses about individuals and test these hypotheses at the appropriate level of analyses. Second, we provide a more rigorous test of hypotheses.

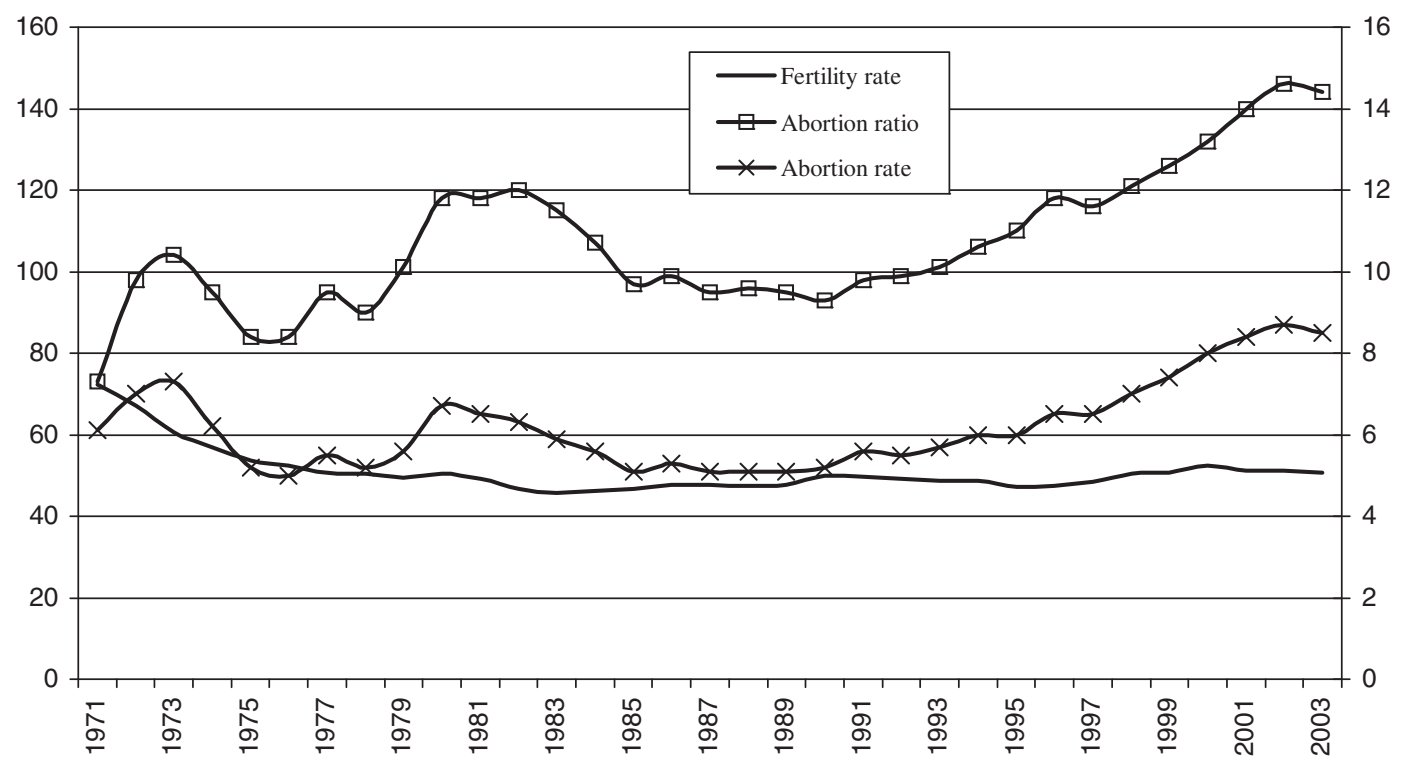

Figure 1 Pregnancy and abortion in the Netherlands between 1971 and 2003 Sources: Wijsen and Van Lee (2006), Statistics Netherlands (2007) and Rademakers (2002). Notes: Abortion rate (scale: 0-16): number of abortions per 1,000 women aged 15-44 years. Abortion ratio (scale 0-160): number of abortions per 1,000 live births. Fertility rate (scale 0-160): number of live births per 1,000 women aged 15-50 years. 
To identify which societal characteristics are relevant for individuals' abortion behaviour we make use of a broad number of empirical findings on reproductive behaviour, from studies conducted in multiple countries and at multiple moments in time. Abortion behaviour can be related to a wide number of societal effects. Estimations of societal effects on individuals' behaviour have to be controlled for possible confounding effects in a multivariate design. Studies that do make use of such a design usually test hypotheses on a very limited number of societal effects (Gius, 2007; Gober, 1997). We simultaneously model commonly suggested determinants on abortion outcomes, thereby providing the most rigid test of hypotheses on abortion law efficacy to date.

The third way in which we make progress pertains to the scope of the explanatory model. Research into abortion behaviour commonly delves into questions regarding the extent to which certain characteristics affect abortion incidence. An exclusive focus on this question is not sufficiently detailed and might even invite paradoxical results. The reason for this is that induced abortion is not a stand-alone act, but results from a process that starts with women's decisions to have sexual intercourse and to use contraceptives, continues with the occurrence of a pregnancy and ultimately ends with the decision to actively terminate that pregnancy. To explain why women eventually have an abortion, this entire process must be examined. There are two reasons why this is important. First, several individual-level characteristics might have different consequences for the probability of experiencing an accidental pregnancy than for the probability to actively end that pregnancy. For example, socioeconomic status negatively affects the likelihood of experiencing an unintended pregnancy, but positively affects the chance that this pregnancy gets terminated (Rossier et al., 2007). If the reproductive process is not adequately accounted for, it is impossible to determine how characteristics ultimately relate to abortion outcomes. Second, several individual and country-level characteristics do not directly affect abortion behaviour. Adequate contraceptive availability does not directly affect women's chances of terminating a pregnancy. Indirectly, its effect might be immense: if effective contraceptives are available, fertility can be better controlled, leading to less unintended pregnancies and to less demand for abortion. We therefore dissect the overarching question on the relationship between characteristics and abortion outcomes into three sub-questions. Our research questions read: to what extent do individual and societal characteristics affect (i) the likelihood that a woman experiences a pregnancy in the Netherlands between 1954 and 2002, (ii) the likelihood that such a pregnancy is unintended, and (iii) the likelihood that such an unintended pregnancy ends in an abortion? We use one theoretical model to answer these three questions. Using retrospective survey data from Statistics Netherlands (2003) we follow 3,793 fertile Dutch women between their 14th and 44th year between 1954 and 2003 and perform repeated event history analyses and sequential logistic analyses to test our hypotheses.

\section{Theory}

Our theoretical model is largely inspired by the economic theory of fertility as developed by Gary Becker (Becker, 1965, 1976, 1991; Becker and Lewis, 1973) and advanced by others to incorporate abortion decisions (Medoff, 1988; Levine, 2004). The choice of having a child is one of potentially life-changing importance. Individuals are prone to make reproductive decisions after giving thought to the costs and benefits of having a child. Costs and benefits are defined in broad terms, which include, but are not restricted to, monetary gains and losses. Financial costs include costs directly related to child-rearing, but also opportunity costs, i.e. the expected loss of time or income related to certain alternative reproductive decisions. Also, psychological and physical costs and benefits may be taken into account when making reproductive decisions. The way in which individuals evaluate costs and benefits depends on certain individual-level traits, such as their education level, their marital status and whether or not they already have children. These individual traits are in part co-dependent on a person's life stage. Women's reproductive decisions are also influenced by their societal context (cf. Del Boca, 2002; Vos, 2009). First, societal contexts-most notably laws-may influence the accessibility of effective contraceptives. As such, macro-level circumstances may affect the likelihood that women experience unintended pregnancies. But they also affect the likelihood that they terminate an unintended pregnancy. Laws are of vital importance here: pregnant women who seek to have an induced abortion may face considerable legal constraints. The degree to which women have access to safe abortion procedures varies within countries over time. Furthermore, the extent to which inducing an abortion financially burdens individuals can be dependent of societal characteristics. Collective health insurance policies may cover expenses related to abortion procedures to various degrees. These societal 
circumstances affect the way in which individuals perceive the various costs or benefits related to the various options. If the societal contexts change, this should affect individuals' behaviour.

\section{Life-course Effects}

The way in which women perceive the costs and benefits of child-rearing depends highly on their life-course. The outcome of reproductive choices is differentiated by age. The effect of age on the chance of pregnancy follows an inverted U-shaped parabolic curve. The likelihood that one terminates a pregnancy is also known to be age dependent. In the Netherlands, as in most Western countries, abortion ratios are higher among women aged 15-24 years, lower among women aged 25-34 years and higher among women aged 35-44 years (Bankole, Singh and Haas, 1999). The chances that women in their fertile age span terminate a pregnancy more or less follow a U-shaped parabolic curve.

These age-related differences can be explained by assuming that individuals make different evaluations of costs and benefits during their life-course. The decision to have an abortion is usually motivated by a combination of reasons, e.g. a desire to stop or postpone childbearing, a desire to continue educational or occupational career, not wanting to interfere with the ability to give care to dependents, not feeling ready to have a child, lacking support from the father and being unable to financially afford another child (Bankole, Singh and Haas, 1998). The relevance of the various factors associated with aborting an unintended pregnancy is found to be strongly dependent of women's age. Younger women who abort a pregnancy more often do so because they wish to continue studying or enter the labour market, women in the maternal stage of their life-course who have an abortion do so more often because they have already given birth to their desired number of children. Older women who end an unintended pregnancy most often do so because they perceive a pregnancy as unsuitable for their work situation (Sihvo et al., 2003). The effects of age on the likelihood of experiencing and terminating a pregnancy can thus at least partly be interpreted by individual characteristics.

First, younger women are more likely to be in school. Child-rearing is time-consuming, which hampers the possibility to invest in education. Teen pregnancies are almost always unintended. We expect that if they are still in school, young women vigorously aim to control their fertility. We expect to observe that school-going women were less likely get pregnant than women who left the educational system. If women did become pregnant while still in school, their pregnancies were more likely to be unintended. The expected negative consequences of an occurring pregnancy for the scholastic success could bear heavily on the decision to give birth or not. Research suggests that these expectations are justified: in New Zealand, e.g., young women who became pregnant before the age of 21 and provoked an abortion to end this pregnancy reached higher levels of educational achievement than comparable women who carried their pregnancy to term (Fergusson, Boden and Horwood, 2007). The found differences in educational outcomes were largely attributable to family circumstances and behavioural, educational and social factors that were already present before the pregnancy. Nonetheless, after controlling for these confounding effects, young women who had an abortion still reached higher levels of educational attainment than those who had carried teenage pregnancies to term remained. Said authors interpret their findings as clear evidence that having an abortion mitigates the educational disadvantage associated with early pregnancy. We expect to observe that when women experienced an unintended pregnancy while still going to school, they were more likely to have an abortion than women who were not at school.

Education affects women's reproductive decisions long after they have left school. Higher educated women postpone childbearing more often (Beets, 2004). Higher educated Dutch women are less likely to experience unintended pregnancies and more likely to abort unwanted pregnancies, especially if they perceive these pregnancies to be too early in their lives (De Graaf and Loozen, 2005). These regularities can be explained by assuming that women weigh opportunity costs in their decision-making process. Such costs are associated with women's time-allocation decisions and can become manifest in situations in which individuals have to accept a lower paying or lower status job than could be expected given their education level. The inability to yield adequate financial returns to their investments in education is perceived as financial loss. All individuals aim to avoid opportunity costs. However, the more one has invested in one's education, the higher the opportunity costs if one cannot pursue a befitting occupational career. We expect that to reduce opportunity costs, higher educated women are likely to control their fertility. If this reasoning makes sense, we should observe that higher educated Dutch women are less likely to become pregnant. Also, we expect to see that the pregnancies of higher educated women were less likely to be unintended. We also extend that higher educated 
women more often turned to induced abortion to end unintended pregnancies.

We expect that the number of children in a household also affects reproductive decisions. Women who have achieved the desired number of children are less likely to become pregnant again. The desired number of children is partly a matter of convention, partly a matter of necessity: raising children is a costly enterprise in terms of time and money. The number of children a family can support is limited. There is also a culturally determined preference: in the Netherlands during the observed period, the desired number of children was two (De Graaf, 2004). We expect that compared to women who already had two children, women who had less than two children would have been more likely to become pregnant and be less likely to regard pregnancies to be unintended. We also expect that compared to women who already had two children, women who had more than two children would have been less likely to become pregnant and be more likely to regard pregnancies to be unintended. In most countries, having the desired number of children is an important reason for having an abortion (Sihvo et al., 2003). We hypothesize that more children made it more likely that women terminated an unintended pregnancy.

Women's reproductive decisions are influenced by their partners. Whether or not a woman is in a relationship strongly influences her reproductive decisions. Having a relationship means that the direct financial costs of child-rearing and the opportunity costs of not being able to work for a while can be shared with a partner. We expect that single women are more likely to control their fertility and less likely to get pregnant and much. We thus hypothesize that when women had a partner, they were more likely to become pregnant than women who did not have partners. Also, when women had a partner, any occurring pregnancies were less likely to be unintended. The absence of a spouse can also affect the likelihood of having an induced abortion to end a pregnancy. In most countries, the lack of the father's support is an important reason for having an abortion (Bankole et al., 1998). We therefore expect that when women had a partner, they were less likely to end a pregnancy.

\section{Effects of Societal Contexts}

Two main types of legislation influence abortion outcomes, i.e. laws about the legality of induced abortion and laws regulating the availability of contraceptive methods. To start with the latter, countries may intend to regulate their population's use of contraceptives. Because a law controlling the actual use of birth control methods would be impossible to uphold, most legislation intended to regulate the use of contraceptives are aimed at regulating distribution. In the Netherlands, distribution of contraceptives was restricted until 1969, when a law that legalized distribution passed both parliament and senate. Under a law that prohibits the distribution of all contraceptives, relatively effective contraceptives will be relatively hard to come by. Women who intend to limit the risk of pregnancy without having to refrain from having sexual intercourse will then turn to contraceptive methods that are more readily available. Such traditional methods typically report a relatively high failure rate, which implies that the women who use them have a higher risk of experiencing a pregnancy. We therefore expect to observe that when contraceptive laws were more permissive, women were less likely to get pregnant. Also, occurring pregnancies were less likely to be unintended. Laws that are specifically aimed at regulating the active termination of pregnancies can stipulate different circumstances under which inducing abortion is considered legal. In the Netherlands, abortion laws have been steadily liberalized during the past 100 years (De Bruijn, 1979). In the early 1940s, Amsterdam court rulings stipulated that an induced abortion necessary to save a woman's life was not illegal and also accepted that a woman's psychological state could be legally considered lifethreatening. This jurisprudence resulted in a 1950s court ruling that legalized abortion to preserve a pregnant woman's mental health. In 1971, Dutch state prosecutors' office decided to refrain from prosecuting physicians who induced abortion on grounds of the pregnant woman's social well-being. While such abortions remained illegal, this decision led to a de facto legalization of abortion for reasons of social well-being. The current Dutch abortion law passed parliament and senate in 1981 and came into effect in 1984. Under this law, provoking abortion is legal provided that an emergency situation exists. The law does not stipulate what constitutes an emergency, thereby de jure legalizing induced abortions on women's request. The only legal limitation pertains to the gestational age: gravidities $>24$ weeks may not be terminated. Restrictive laws influence women's decision to actively end a pregnancy in two main ways. First, practitioners who perform illegal abortions usually run the risk of losing their medical license and go to jail. If the law is upheld effectively, practitioners are more likely to refrain from performing such procedures. Second, the laws are intended to have a deterring 
effect on women. If the law is upheld effectively, individuals who are faced with a decision to have an abortion under circumstances that are not considered legal will risk prosecution. This risk is factored into the decision-making process as a considerable constraint, reducing the probability that a woman will choose to terminate a pregnancy illegally. Under more permissive laws, fewer acts of abortion are considered punishable. For both reasons, we expect to observe that the more permissive the law on abortion was, the more likely it was that pregnant women have an induced abortion.

A focus on the legal context does not fully explain women's abortion behaviour. Laws are not always upheld effectively, and even if they are, there are always those who are willing to run the risk of getting caught and being punished. Moreover, if legislative constraints are absent, individuals' behavioural alternatives are restricted by the extent to which they have access to services. We explore the extent to which the availability of contraceptives and the availability of safe abortion procedures affect women's chances of experiencing a pregnancy and provoking an induced abortion. Sexually active women who want to prevent a pregnancy have several contraceptive methods at their disposal, including traditional and natural methods, barrier methods, intrauterine devices, and hormonal methods. Although their use is not without health risk, hormonal contraceptives are widely used throughout the Western world. The main reason for their popularity lies within their relative reliability and relatively low failure rate. We infer from this that women evaluate the relative reliability of the available contraceptive methods and subsequently choose the most effective method available. We formulate a hypothesis on the availability of the birth control pill. The pill was first introduced in the Netherlands in 1962 and immediately became very popular (Rensman, 2006). Although since 1962 its popularity fluctuated somewhat due to negative media coverage, it is the most widely used method of contraception for Dutch women (De Graaf, 2004). After 1962, the more widely the pill was available, the more control women had over their fertility. Better control would lead to lower fertility and fewer unintended pregnancies. If this line of reasoning is correct, we should observe that when the birth control pill was more available, the less likely it was that Dutch women experienced a pregnancy. We should also observe that higher availability of the pill resulted in fewer unintended pregnancies.

Even modern contraceptives are not 100\% reliable. Contraceptive failure is a major reason for having an abortion in the Netherlands (Kruijer, Van Lee and Wijsen 2009). Women who want to terminate an unintended pregnancy can turn to various abortion methods. The extent to which various methods are available varies over time. At the beginning of the 20th century, Dutch women were still self-inducing abortions by potentially dangerous traditional methods. With the development of medical technology during the 20th century, the number of available abortion methods increased (De Bruijn, 1979). Due to the illegal status of induced abortion in the Netherlands during the better part of that century, procedures were often performed by unqualified abortionists, whose dilettante methods could lead to serious health risks for the women involved (De Bruijn, 1979). Dutch women became considerably less dependent of possible unsafe abortion procedures in 1967, when Dutch hospitals defied the law and started to assemble so-called abortion teams to deal with the high demand for safe abortion procedures (Ketting, 1978). These multidisciplinary teams operated illegally but were nonetheless comprised of highly qualified medical personnel, including gynaecologists, doctors-of-medicine, psychiatrists, psychologists, and social workers (De Bruijn, 1979). The first medical clinics that had the sole purpose of performing abortions were founded in 1971, and many such abortion clinics were founded in the following years (Ketting and Schnabel, 1980). With the 1984 abortion law, the Dutch government legalized these clinics, but intended to regulate their practices. Subsequently, the clinics and their personnel became subject to intense governmental monitoring, to ensure the highest possible safety levels. Since 1984, the number of clinics has largely remained the same (Inspectie voor de Gezondheidszorg, nd). The extent to which women have access to safe abortion providers is positively correlated with abortion rates in the United States (Gius, 2007; Gober, 1997). We propose that the physical costs of an induced abortion increase when the expected health risks related to the abortion procedure are higher. We expect that the availability of safe abortion procedure reduces the potential physical costs related to abortion. We further assume that the relative ease with which women have access to safe procedures increases with the number of hospitals and clinics that offer such safe procedures. If this reasoning is correct, we should observe that the easier it was to have access to safe abortion services, more likely it was that pregnant women had an induced abortion.

The general availability of reliable contraceptive methods and safe abortion procedures does not necessarily imply that such methods are equally obtainable by all who demand them. Financial costs 
might influence the decision between available methods. If relatively reliable and safe methods of contraception are available on the market but relatively expensive, women who cannot afford using these methods are forced to use less reliable alternatives. One of the means with which the use of effective contraceptives can be promoted is by governmental policies that include the costs of contraceptive use in public health insurance. In the Netherlands, the costs of the birth control pill were fully covered by public health insurance between 1968 and 2004, which effectively reduced individuals' financial costs for obtaining the pill in this period to nil (Treffers, 2006). The relatively low costs of effective contraceptives have been suggested to partly explain the relatively low number of unwanted teenage pregnancies (Ketting and Visser, 1994; De Graaf, 2004). Since 2004 the birth control pill is no longer covered by Dutch health insurance for women over the age of 21. A recent study shows that the birth control pill is still the most popular method of contraception among Dutch women, but that the number of pill users has declined (De Graaf, 2009). Although the reasons for this decline have not been extensively studied, at least one study links this decline to the fact that the pill was no longer insured (Rutgers Nisso Groep, 2004). We propose that in circumstances in which effective contraceptives are relatively expensive, women may either turn to traditional and thus less reliable methods of contraception or even refrain from using contraceptives altogether. Both decisions would have a measurable impact on individuals' chances of getting pregnant. If this is true, we should observe that when the costs of acquiring effective contraceptives were covered by collective health insurance, women were less likely to experience pregnancy, and pregnancies were less likely to be unintended. A similar reasoning then explains women's propensity to induced abortion. Most research into the effects of inclusion of abortion in collective health insurance has been done in the United States (cf. Haas-Wilson, 1993, 1997). Between 1976, when the Hyde Amendment that severely restricted Medicaid funding of induced abortion came into effect, and 1980, when the US Supreme Court ruled this amendment unconstitutional, a considerable group of women of poor financial means who could not afford to obtain an abortion consequently either carried their unwanted pregnancies to term, or subdued themselves to alternative, often unsafe abortion methods (Trussel et al., 1980). We aim to test the effect of collective coverage in the Netherlands. In the Netherlands, induced abortion became part of government insurance policies in 1985. If collective coverage in the Netherlands has similar effects as in the United States, we expect to observe that when the costs related to induced abortion were covered by collective health insurance, women were more likely to terminate a pregnancy.

\section{Macro-economic Conditions}

Although the direction of the causal relationship is subject to debate, the association between female employment and fertility remains largely undisputed (Bernhard, 1993). For the better part of the 20th century, female labour participation rates have been negatively correlated with fertility rates. These effects are moderated by other societal circumstances. Evidence suggests that this macro-level relationship has switched sign in the 1980s (Brewster and Rindfuss, 2000; Ahn and Mira, 2002). This recent positive macro-level relationship between female labour participation and fertility rates has been attributed to wider labour market conditions: labour markets with higher general unemployment rates depress fertility, because young women postpone childbearing to be able to invest in their education, both to ensure a life-time income and to avoid immediate unemployment (Adserà, 2004; Da Rocha and Fuster, 2006). Research in the United States (Medoff, 1988) and Sweden (Rahmqvist, 2006) indicates that unemployment levels also affect abortion outcomes. In Sweden, e.g., rising unemployment is associated with lower fertility and, because the relative number of abortions is more or less constant, a lower number of abortions (Rahmqvist, 2006). Given the apparent relevance of the macro-economic context for both the likelihood of getting pregnant and the likelihood of having an abortion, we must control our parameter estimates for this economic context. When testing our hypotheses, we control for the macro-level influence of female labour market participation and general unemployment.

\section{Methods}

To test our hypotheses, we analyse retrospective event history data with discrete time repeated event history analyses. By simultaneously examining women's fertility histories and their educational and relational careers, it is possible to better distinguish cause and effect. Comparably, event history techniques allow for examining the influence of changes of societal conditions (Barber et al., 2000). Event history techniques model hazard rates, defined as the probability that individuals experience an event during a particular 
period of observation, under the condition that these individuals are at risk at that time. The hazard rates are unobserved variables; the observed dependent variables are dichotomous variables scored (1) each year a woman experiences the event and (0) in all other years. As argued, we do not regard the act of abortion as a single event. To analytically account for the process leading towards abortion, we dissect the pregnancy termination event into sequential dichotomies. A pregnancy serves as conditio sine qua none for all the subsequent steps in the process. Therefore, we first perform a repeated event history analysis on the likelihood of experiencing a pregnancy. We then perform sequential logistic regression analyses to determine the effect of predictors on the likelihood that occurring pregnancies are unintended. The final step in this sequence is the decision to either terminate an unintended pregnancy or carry it to terms, which we again analyse using logistic regression. Each of the sequences has a different risk set. We analyse the likelihood of experiencing a pregnancy using a the risk set that contains all fertile women. However, a woman is at risk of experiencing an unintended pregnancy only when she is pregnant. Also, only unintended pregnancies are at risk of being terminated. Because a woman can experience multiple pregnancies and multiple abortions, we analyse our data using multilevel techniques.

\section{Data}

Event history uses data that are structured as longitudinal records, indicating whether or not individuals experienced the event of interest at a certain moment during a period of observation. Our analyses thus necessitate the use of large-scale longitudinal or retrospective data that contain information about whether or not respondents ever experienced a pregnancy, and experienced and ended an unexpected pregnancy and if so, in what year these events occurred. The 2003 wave of the Netherlands' Family and Fertility Survey (FFS) [Onderzoek Gezinsvorming (OG)] is the only recent Dutch data set that holds sufficiently detailed retrospective information about pregnancies that are not carried to term. Conducted by Statistics Netherlands (2003) and instigated five yearly, the survey is aimed at gathering information about trends in relationships and family formation in the Netherlands. Information about fertility histories was obtained by face-to-face interviews held by female interviewers using computer-aided questionnaires. Information was gathered about the number of children respondents had, as well as on the age of these children. Fertile heterosexual women were asked about the number of unintended pregnancies they had experienced, as well as on the timing in years and outcome of the first and second or last of these unintended pregnancies. A two-step procedure was used. The verbatim English translation of these questions read:

1. 'Did you ever get pregnant while you did not intend to?' If the answer to this question was affirmative, women were asked:

2. 'How often did this happen?' Subsequently, these women were asked the question:

3. 'How old were you when you got pregnant unintended for the first time?'

4. 'How did this [first] unintended pregnancy end?', on which women could answer (a) live birth, (b) still birth, (c) miscarriage, (d) induced abortion, (e) still pregnant.

If women answered to the second question that they had experienced more than one unintended pregnancy, the third and fourth questions were repeated to obtain information on the last experienced unintended pregnancy.

The FFS data contain information from a random sample of 4,229 Dutch women born between 1940 and 1984. Not all of these respondents could be analysed. Eighteen women were infertile their entire lives. For 129 women, crucial information about the timing of occurring pregnancies was missing, making it impossible to include them in our analyses. We excluded respondents who did not have valid scores on these crucial variables, losing information on 37 unintended pregnancies. Furthermore, nineteen women reported to have experienced an unintended pregnancy more than twice, resulting in a total number of 32 unintended pregnancies on which the raw data do not contain information. A number of 289 women spent more than one full year in country other than the Netherlands. The data did not contain information about which countries these women lived in. Since we were also interested in societal effects deriving from the Dutch context, we excluded all women who had spent $>1$ year of their life abroad. ${ }^{1}$

Using available information about respondents' fertility history, we restructured the data into an event history data structure. The data did not allow for the distinction of the year in which women became sexually active, but do allow for following women during their entire fertile life span. Because they had no possibility of getting pregnant, we did not analyse women from the moment they became sterilized or 
became infertile for any other reason. The file contains a record for each year in fertile women's lives, starting at the age of 14 and ending at age 44 or, in the event that a woman became infertile at an earlier age, at the age of infertility. If at the time of the interview, the respondent still had not reached the age of 44 and was still able to give birth, we kept a record for each year up until 2002. In total, we were able to analyse $N=3,793$ women. We observed these women for a total of $\mathrm{N}_{O B S}=87,375$ person-years, during which the women reported $\mathrm{N}_{P}=5,746$ pregnancies. Of these pregnancies, $\mathrm{N}_{U P}=468$ were considered to be unintended. $\mathrm{N}_{A B}=112$ unintended pregnancies ended in an induced abortion.

\section{Variables}

Respondents were questioned on relevant background variables. Each person-period record contains information of a woman's characteristics in a given year. These characteristics vary over time. We added time variant information on societal properties. We will briefly discuss the operationalization of our measurements. Descriptive statistics of all used variables are presented in Table 1.

\section{Abortion}

Dummy variable, scored (0) in all years except in those years in which an Unintended pregnancy was reported to have ended in an abortion (1).

\section{Unintended pregnancy}

Measured dichotomously, scored (0) in all years except in each year a woman reported an unintended pregnancy (1).

\section{Pregnancy}

Dichotomous measure, scored (0) in all years except in each year a woman was pregnant (1). We combined information about the birth years of respondents' natural children with information about unintended pregnancies. Respondents were asked how many children they had within and outside their household, and in what year these children were born. Reasoning that the women would have to have been pregnant prior to the birth of a living child, we calculated the ages at which they had been pregnant. We also used information about the reported timing of unintended pregnancies.

\section{Age}

We measure respondents' age with a quadratic function.

\section{School-going}

Dummy variable. We used information on the highest completed education level, the average number of years it takes to achieve that level of education and the respondent's age to infer whether (1) or not (0) a respondent was still in school in a given year.

\section{Education level}

Based on the years of schooling minimally required to achieve the respondent's reported ultimate education level, we computed the education level for each year in the respondent's life. The scale is coded as follows: (0) primary education; (1) lower secondary education; (2) higher secondary education; (3) tertiary education. The scale is used as an interval variable.

\section{Number of Children}

A set of dummy variables, indicating whether the number of children in the interviewed women's household was zero (0), one (1), two (2), three (3), or more than three (4). Women with two children are reference.

\section{Partner}

The data contain direct information about respondents' relational histories. For the purpose of testing our hypotheses, the distinction between married and cohabiting women does not matter. Both marriage and cohabitation are solid relationships. For each year in the respondent's life, we thus measured whether or not she was married or cohabiting (1), or not (0).

\section{Law on contraception}

In the Netherlands, distribution of contraceptives was restricted until 1969, when a law that legalized distribution passed both parliament and senate. We measure the permissiveness of the law on contraceptives with a time-variant dummy variable, valued (0) for each year that the distribution of contraceptives was considered illegal, and (1) for each year that the distribution of contraceptives was not prohibited by law (i.e. 1969-2002).

\section{Law on abortion}

A set of dummies, indicating whether abortion was legal if a woman's mental health was in danger (each year until 1971), or abortions for socio-economic reasons were de facto legal (each year from 1971 to 1984). The dummy indicating that abortion was considered legal under all circumstances (i.e. from 1984 to 2002) is reference and not included in the analyses. 
Table 1 Descriptive statistics of measures

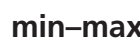

Fertile
Mean (std. dev)

Pregnant

Mean (std. dev)

Unintended

Mean (std. dev)

\begin{tabular}{|c|c|c|c|c|}
\hline \multicolumn{5}{|l|}{ Event of interest } \\
\hline Pregnancy & $0-1$ & $0.066(0.248)$ & NA & NA \\
\hline Unintended pregnancy & $0-1$ & $0.005(0.073)$ & $0.081(0.274)$ & NA \\
\hline Abortion & $0-1$ & $0.001(0.036)$ & $0.020(0.138)$ & $0.239(0.427)$ \\
\hline \multicolumn{5}{|l|}{ Life-course effects } \\
\hline Age & $14-44$ & $26.654(8.516)$ & $27.171(4.667)$ & $25.481(6.583)$ \\
\hline In school & $0-1$ & $0.256(0.436)$ & $0.038(0.190)$ & $0.150(0.357)$ \\
\hline Education level & $0-3$ & $1.298(0.955)$ & $1.587(0.909)$ & $1.310(0.971)$ \\
\hline No children & $0-1$ & $0.586(0.493)$ & $0.472(0.499)$ & $0.474(0.500)$ \\
\hline One child & $0-1$ & $0.118(0.323)$ & $0.364(0.481)$ & $0.212(0.409)$ \\
\hline Two children & $0-1$ & $0.204(0.403)$ & $0.130(0.336)$ & $0.201(0.401)$ \\
\hline Three children & $0-1$ & $0.075(0.263)$ & $0.031(0.172)$ & $0.088(0.283)$ \\
\hline More than three children & $0-1$ & $0.017(0.130)$ & $0.004(0.065)$ & $0.026(0.158)$ \\
\hline Partner & $0-1$ & $0.571(0.495)$ & $0.919(0.272)$ & $0.718(0.451)$ \\
\hline \multicolumn{5}{|l|}{ Societal effects } \\
\hline Contraceptives sales legal & $0-1$ & $0.913(0.282)$ & $0.920(0.272)$ & $0.857(0.351)$ \\
\hline Abortion legal: mental health & $0-1$ & $0.116(0.320)$ & $0.126(0.331)$ & $0.190(0.393)$ \\
\hline Abortion legal: SES & $0-1$ & $0.297(0.457)$ & $0.315(0.464)$ & $0.250(0.434)$ \\
\hline Abortion legal: on request & $0-1$ & $0.587(0.492)$ & $0.560(0.497)$ & $0.560(0.497)$ \\
\hline Birth control availability & $0-45.5$ & $32.427(11.476)$ & $32.291(11.170)$ & $30.817(12.857)$ \\
\hline No. of abortion clinics & $0-22$ & $15.479(6.256)$ & $15.069(6.524)$ & $14.109(7.428)$ \\
\hline Birth control pill insured & $0-1$ & $0.868(0.339)$ & $0.850(0.358)$ & $0.793(0.406)$ \\
\hline Abortion insured & $0-1$ & $0.556(0.497)$ & $0.533(0.499)$ & $0.547(0.498)$ \\
\hline Female labour participation & $24.00-44.84$ & $32.080(6.954)$ & $32.019(7.195)$ & $32.206(7.404)$ \\
\hline Unemployment rate & $0.17-4.27$ & $2.061(1.111)$ & $1.947(1.111)$ & $1.825(1.151)$ \\
\hline $\mathrm{N}_{\text {persons }}$ & & 3.793 & 2.632 & 408 \\
\hline $\mathrm{N}_{\text {observations }}$ & & 87,375 & 5,746 & 468 \\
\hline
\end{tabular}

Source: Statistics Netherlands (2003).

Availability of birth control pill

The birth control pill became available in the Netherlands in 1962. Direct information on its availability is not public. To be able to measure the general use of the pill, we reconstructed the percentage of women between 16 and 49 who yearly use the birth control pill in all years from 1962 as an operationalization for general availability. We use a 1-year time lag to deal with causality issues. Information was obtained from Rensman (2004), Statistics Netherlands (2008a) and Bronsema and Moors (1994).

\section{Access to safe abortion services}

We counted the yearly number of licensed abortion clinics that were operating in the Netherlands. We use a time lag of 1 year. In all years preceding 1972, this variable is scored $(0)$. Clinics are included in a year's count if they are founded in that particular year, or if they are operational during the entire year. Clinics that have closed in a particular year are not included in that year's count. Information about the opening and closing dates of clinics was obtained from the Netherlands' Health Care Inspector (Inspectie voor de Gezondheidszorg, nd).

\section{Collective insurance of birth control pill}

The costs of the birth control pill were covered by Dutch public health insurance as of 1968 . We include a dummy variable, valued (0) in the years preceding 1968, and (1) from 1968 to 2002.

\section{Collective insurance of abortion procedure}

Induced abortion became part of government insurance policies in 1985 . We thus analyse a dichotomous variable, scored (0) in the years preceding 1985, and valued (1) from 1985 to 2002. 


\section{Female labour market participation rates}

For each year between 1954 and 2002, we calculated the percentage of Dutch women over 14 years old who were active on the labour market. Information was obtained from Statistics Netherlands (2008c).

\section{Unemployment rates}

Using information from Statistics Netherlands (2008b), we calculated the number of unemployed Dutch adults per 1,000 Dutch inhabitants between 1954 and 2002. The variable has a range from 0.174 (in 1964) to 4.268 (in 1983).

\section{Results}

The effects of our predictors on the occurrence of three events are estimated in four separate models. ${ }^{2}$ Model A estimates the effects of independent variables on the likelihood of getting pregnant. In this model, all fertile women are at risk. In model B, only pregnant women are at risk, and the relationships of the relevant determinants on the likelihood that a pregnancy is unintended are explored. In models C and D, we present the effects of the various predictors on the likelihood of terminating an unintended pregnancy. We discuss the effects of each predictor on the occurrence of all three events, and thus switch back and forth between the models to test hypotheses. We present all estimated parameters in Table 2.

\section{Life-course Effects}

We first test our hypotheses on the effects of being in school on the various stages in the reproductive process that ultimately lead to an induced abortion. As model A shows, Dutch women were less likely to experience a pregnancy if they were in school $(b=-0.763)$. Model $\mathrm{B}$ indicates that school-going women were more likely to experience pregnancies to be unintended $(b=0.819)$. Both models C $(b=1.706)$ and $\mathrm{D}(b=1.652)$ show that school-going women were also more likely to terminate unintended pregnancies.

Table 2 also provides insight in the extent to which education influences the chain of reproductive events that precede a possible abortion. We find that one's education level negatively affected the likelihood of experiencing a pregnancy $(b=-0.054)$. However, model B seems to indicate that higher educated women were not less likely to experience an unintended pregnancy $(b=0.000)$. Additional analyses (available from author) have shown that higher educated
Dutch women are less likely to experience pregnancies to be unintended. This is in line with common research findings (De Graaf and Loozen, 2005). However, when we control these effects for the women's age at the time of their respective pregnancies, the differences between higher and lower educated women disappear. The differences between higher and lower educated women are fully explained by the fact that they are-in general—pregnant at different points in their lives. We also find no evidence that higher educated women are more likely to terminate unintended pregnancies (Models C and D). Studies have shown that higher educated women in many countries are more likely to have an induced abortion, but less likely to have an unintended pregnancy. It is often postulated that these associations are applicable to Dutch women and that the rise of the general education level of the Dutch female population consequently provides an explanation for the relatively low abortion incidence. Dutch women with a higher education have a higher probability to terminate their first unintended pregnancy (De Graaf and Loozen, 2005). We do not find evidence for this correlation when we look at all unintended pregnancies. Turning to assessing hypotheses about the effects of the number of children a woman has, model A shows that the number of children in the household affects the likelihood of experiencing a pregnancy. As expected, women who had no children $(b=1.438)$ or one child $(b=1.889)$ are more likely to become pregnant than women who have two children, and much less likely to regard occurring pregnancies as unintended (Model B: $b=-1.790$ and $b=-1.488$, respectively). Women who have more than two children are less likely to become pregnant, and more likely to regard a pregnancy to be unintended. This is in line with earlier findings that have shown that in the Netherlands, women on average desire two children (De Graaf, 2004). Having the desired number of children is also an important reason for terminating the first unintended pregnancy (De Graaf and Loozen, 2005). However, in general, the number of children does not significantly affect the chances that women terminate unintended pregnancies. To conclude the assessment of life-course effects, we now turn to discussing the effects of having a partner. As hypothesized, having a partner increased the likelihood that a woman experiences a pregnancy (Model A: $b=2.131$ ) and decreased the chance that a woman deem pregnancies to be unintended (Model B: $b=-1.796$ ). As is shown in models $\mathrm{C}$ and $\mathrm{D}$, any unintended pregnancies that did occur were considerably less likely to be terminated if women had a partner. 
Table 2 Sequential logit models: effects on the likelihood that fertile women experience a pregnancy, the likelihood that a pregnancy is unintended likelihood that an unintended pregnancy will end in an abortion

\begin{tabular}{|c|c|c|c|c|c|c|c|c|}
\hline \multirow[b]{2}{*}{ Predictors } & \multicolumn{2}{|c|}{$\begin{array}{l}\text { A } \\
\text { Pregnancy } \\
\text { if fertile }\end{array}$} & \multicolumn{2}{|c|}{$\begin{array}{l}\text { B } \\
\text { Unintended } \\
\text { if pregnant }\end{array}$} & \multicolumn{2}{|c|}{$\begin{array}{l}\text { C } \\
\text { Abortion } \\
\text { if unintended } \\
\text { pregnancy }\end{array}$} & \multicolumn{2}{|c|}{$\begin{array}{l}\text { D } \\
\text { Abortion if } \\
\text { unintended } \\
\text { pregnancy }\end{array}$} \\
\hline & B & S.E. & B & S.E. & B & S.E. & B & S.E. \\
\hline Constant & $-17.236^{\star \star}$ & 0.502 & $16.337^{\star \star}$ & 1.473 & -4.207 & 3.870 & -2.839 & 3.855 \\
\hline \multicolumn{9}{|l|}{ Life-course effects } \\
\hline $\mathrm{Age}^{\sim}$ & $0.888^{* *}$ & 0.033 & $-1.124^{\star *}$ & 0.101 & 0.162 & 0.274 & 0.145 & 0.271 \\
\hline $\mathrm{Age}^{2 \sim}$ & $-0.016^{\star *}$ & 0.001 & $0.018^{\star *}$ & 0.002 & $<0.001$ & 0.005 & $<0.001$ & 0.005 \\
\hline In school $\sim$ & $-0.763^{* *}$ & 0.084 & $0.819^{* *}$ & 0.223 & $1.706^{*}$ & 0.700 & $1.652^{*}$ & 0.681 \\
\hline Education level $^{\sim}$ & $-0.054^{\star}$ & 0.025 & 0.000 & 0.076 & -0.262 & 0.253 & -0.206 & 0.246 \\
\hline No children $\sim$ & $1.438^{* *}$ & 0.075 & $-1.790^{\star *}$ & 0.189 & 0.105 & 0.663 & 0.098 & 0.649 \\
\hline One child ${ }^{\sim}$ & $1.889^{* *}$ & 0.059 & $-1.488^{\star *}$ & 0.173 & -0.174 & 0.644 & -0.244 & 0.635 \\
\hline Two children ${ }^{\sim}$ & (ref.) & - & (ref.) & - & (ref.) & - & & \\
\hline Three children $\sim$ & $-0.651^{\star *}$ & 0.097 & $0.919^{* *}$ & 0.242 & -1.168 & 0.858 & -1.131 & 0.838 \\
\hline More than three children ${ }^{\sim}$ & $-1.500^{* *}$ & 0.232 & $2.210^{* *}$ & 0.512 & -2.993 & 1.721 & -3.094 & 1.737 \\
\hline Partner $\sim$ & $2.131^{* *}$ & 0.060 & $-1.796^{* *}$ & 0.184 & $-2.396^{\star *}$ & 0.624 & $-2.247^{* *}$ & 0.594 \\
\hline \multicolumn{9}{|l|}{ Societal effects } \\
\hline Contraceptives sales legal ${ }^{\sim}$ & $-0.185^{\star}$ & 0.087 & $-0.659^{\star}$ & 0.277 & & & & \\
\hline Abortion legal: mental health ${ }^{\sim}$ & & & & & (ref.) & - & & \\
\hline Abortion legal: SES $\sim$ & & & & & $2.255^{*}$ & 0.988 & & \\
\hline Abortion legal: on request ${ }^{\sim}$ & & & & & $3.050^{*}$ & 1.417 & & \\
\hline Birth control pill availability $\sim$ & $-0.018^{\star *}$ & 0.004 & -0.005 & 0.014 & & & & \\
\hline No. of abortion clinics $\sim$ & & & & & & & $0.195^{* *}$ & 0.067 \\
\hline Birth control pill insured ${ }^{\sim}$ & $-0.283^{\star *}$ & 0.099 & 0.173 & 0.351 & & & & \\
\hline Abortion insured $^{\sim}$ & & & & & & & 0.868 & 0.802 \\
\hline Female labour participation $\sim$ & $0.038^{* *}$ & 0.004 & 0.022 & 0.015 & -0.087 & 0.057 & $-0.131^{*}$ & 0.061 \\
\hline Unemployment rate $^{\sim}$ & $-0.174^{\star *}$ & 0.019 & $0.147^{\star}$ & 0.067 & 0.264 & 0.260 & -0.074 & 0.275 \\
\hline Variance component & 0.680 & 0.039 & 0.747 & 0.173 & $2.133^{*}$ & 0.744 & 2.055 & 0.709 \\
\hline$-2 L L$ & \multicolumn{2}{|c|}{$33,310.886$} & \multicolumn{2}{|c|}{$2,593.132$} & \multicolumn{2}{|c|}{421.756} & \multicolumn{2}{|c|}{415.804} \\
\hline $\mathrm{N}_{\text {persons }}$ & \multicolumn{2}{|c|}{3,793} & \multicolumn{2}{|c|}{2,632} & \multicolumn{2}{|c|}{408} & \multicolumn{2}{|c|}{408} \\
\hline $\mathrm{N}_{\text {observations }}$ & \multicolumn{2}{|c|}{87,375} & \multicolumn{2}{|c|}{5,746} & \multicolumn{2}{|c|}{468} & \multicolumn{2}{|c|}{468} \\
\hline
\end{tabular}

Notes: $\sim$ time-varying covariate.

${ }^{*} P<0.05,{ }^{*} P<0.01$. The presented data are estimated effects on the log odds for experiencing a pregnancy given fertility, experiencing a pregnancy to be unintended and terminating an unintended pregnancy.

Source: Statistics Netherlands (2003), own computations.

\section{Societal Characteristics}

Now turning to discussing the effects of societal characteristics on the events that might lead towards an abortion, we first discuss the effects of laws. We find evidence to suggest that individuals' behaviour is influenced by the law. Our analyses show that a more permissive contraceptive law corresponded with a lower likelihood of experiencing a pregnancy $(b=-0.185)$ and a lower likelihood that pregnancies were unintended $(b=-0.659)$. We thus might infer from these estimates that a more lenient contraceptive law indeed enlarges the level of control women have over their reproductive behaviour. In model C, it becomes apparent that more liberal abortion laws were associated with a higher likelihood that unintended pregnancies were aborted. The effect of laws on abortion outcomes is commonly assumed, but literature does not unambiguously find macro-level correlations between countries' abortion laws and their aggregate abortion outcomes. Our findings indicate that in the Netherlands, women were more likely to terminate unintended pregnancies when the law legalized more reasons for abortion.

Higher availability of birth control pills as measured by a larger proportion of the female population using 
such pills is associated with lower fertility $(b=-0.018)$ but not with lower probability of experiencing unintended pregnancies. Additional analyses (not presented) reveal that the effect of pill availability on the likelihood of experiencing an unintended pregnancy is fully interpreted by the effect of having a partner. An explanation might be that unintended pregnancies are mostly experienced by women who are not notably affected by pill availability. Women who were not more prone to make more use of these methods when they became better available might have been more at risk of unintended pregnancies even before the introduction of the pill. Our analyses also indicate that women are more likely to abort unintended pregnancies if abortion services are more readily available $(b=0.195)$. Also, when the birth control pill was covered by collective insurance, the likelihood of experiencing a pregnancy was lower $(b=-0.283)$. Insurance of the pill did not reduce the occurrence of unintended pregnancies. This might be explained by the fact that women switch to other available reliable methods. Two recent studies show that the lower use of the contraceptive pill is partly compensated by the use of intra-uterine devices or sterilization (De Graaf, 2004, 2009). The collective insurance of abortion was not associated with a higher number of terminated unintended pregnancies.

\section{Conclusion and Discussion}

Dutch women seeking an abortion have not faced serious constraints for the past quarter of a century. The permissive abortion law, easily accessible abortion providers and the absence of financial costs do little to prevent women from having an abortion should they choose to have one. Nonetheless, the Netherlands are among the counties with the lowest abortion incidence in the world. Previous research suggests a variety of possible explanations. In the most comprehensive simultaneous test of hypotheses to date, we examined whether these possible explanations hold. We make no claim to have definitely solved the Dutch abortion paradox: as always in such analyses, the low abortion incidence might be explained by variables that are not included in the models. Macro-level hypotheses about the norms regarding sexuality, the role of sex education and the mass media could not be tested by a lack of data. Although the data we analysed are the most recent and most elaborate retrospective individual-level data available on the subject of abortion in the Netherlands, our data lacked important information.
Possibly interesting hypotheses thus remained untested. We will discuss the three most important ones. First, labour force participation is known to affect reproductive behaviour. Although there are large cross-national differences, the relationship between individuals' labour force participation and their fertility is negative in most countries (Brewster and Rindfuss, 2000). This is often theoretically explained by assuming that labour force participation raises women's costs of child-rearing, because of foregone wages. If this is true, it is to be expected that women who are employed are more likely to terminate unintended pregnancies. Our data lacked individuallevel retrospective information on employment status, which prevented us from testing hypotheses the effect of employment directly. It should be stressed, however, that research into the economic conditions of women would most probably not add to further explaining the Dutch paradox. The Netherlands has been among the most affluent and economically advanced Western countries with a labour market that has steadily opened up to women between 1954 and 2002. We would expect to observe relatively high abortion incidence in the Netherlands, if compared to other Western countries. Second, we could not examine partner effects, since our data did not contain retrospective information on women's partners. We argued that women who have a partner can share the costs of rearing a child, both in terms of financial costs and in terms of time-allocation decisions. The way women (and their partners) make these decisions partly depends on partners' characteristics, most notably their employment status, educational attainment and income. Having a partner would compensate the effect of one's own vulnerable economic position. Although our analyses clearly support the hypotheses that partners are important, our measurement of partner effects is very rudimentary. Further research into partner effects is clearly warranted, if not called for. A third possibly interesting individual-level hypotheses we could not test pertains to religiosity. Religiosity is often argued to be positively correlated with fertility and negatively contraceptive use and the likelihood of having an abortion. We would expect to observe that on the individual level, religiosity does affect abortion behaviour. Unfortunately, retrospective information about religiosity was missing, making it impossible to test this hypothesis. On the other hand, Dutch women are not overly religious. In terms of both religiosity and religious practices, the Netherlands are among the more moderate countries in Europe (Halman and Draulans, 2006). Moreover, during most of the period covered in our study, religiosity has been in decline in 
the Netherlands (De Graaf and Te Grotenhuis, 2008). Therefore, religiosity is unlikely to explain why the Dutch abortion rate is so much lower than that in other countries. Fourth, retrospective information about women's place of residence was not available, making it impossible to include immigrants in our data. This is problematic, because the growing proportion of immigrant women in Dutch society has been linked to the slight rise in the Dutch abortion rate (Wijsen, Van Lee and Koolstra, 2007). We could not test this important hypothesis.

So how do our analyses add up to conclusions about the Dutch paradox? Our analyses provide insight in the way in which micro- and macro-level qualities affected fertility behaviour of Dutch women and can thereby certainly contribute to explaining the paradox. Our analyses show that women who face decisions about pregnancies, giving birth or having an abortion do so based upon their personal situation, but also take their societal context into account. The reproductive process leading to abortion provides essential insights in how individual and societal characteristics affect abortion outcomes. Being in school decreases the likelihood of getting pregnant and increases the probability that a woman terminates an occurring unintended pregnancy. After the second child, the more children a woman has, the less likely she will have another pregnancy. Having a partner increases the chance that a woman gets pregnant and decreases the chance that she terminates a pregnancy. Higher educated Dutch women are less likely to experience a pregnancy. If pregnant, they are not more likely to have an abortion than comparable lower educated women. Our analyses offer some ground for the cautious conclusion that the relatively low Dutch abortion incidence cannot be fully explained by specific compositional make-up of Dutch society. For example, compare the Dutch population to populations of other European countries on the relevant individual-level characteristics. Three examples will suffice to illustrate our point. First, the Netherlands are among the European countries with the longest compulsory education tracks (children are obliged to go to school until they are 18-years old), which means that more children spend more time in school for a longer period in the Netherlands than in other European countries. Our analyses indicate that being in school increases the probability that women have an abortion to end an unintended pregnancy. If going to school would be the only determinant for terminating pregnancies, we would expect to observe a relatively high Dutch abortion rate compared to other European countries. A similar argument can be made pertaining to the effects of individuals' education level. On average, Dutch women are somewhat less frequently higher educated than women in the Nordic countries, but more frequently higher educated than, say, women in Portugal (Beck-Domzalska, 2007). Also, Dutch women on average are less likely to be single than women in Italy, Spain or Portugal, but not less likely to be single than women in the Nordic countries (Kiernan, 2002). Yet, abortion occurs much less often in the Netherlands than in any of said countries. Although multilevel analyses on data from multiple countries are clearly needed to disentangle compositional and contextual effects and further test the above-mentioned statements, it seems reasonable to conclude that factors not related to compositional differences must be at work.

Our main contribution is the extent to which we are able to test hypotheses on country characteristics. In the most elaborate analyses of country characteristics to date, we show that societal features indeed affected individuals' probability of having an induced abortion. First, abortion laws do affect abortion behaviour. We find that if abortion was legally available on request, individual women were more likely to terminate an unintended pregnancy. Second, the more available abortion clinics were, the more likely it was that women terminate an occurring pregnancy. Whether or not abortion was collectively insured did not affect individuals' propensity to end a pregnancy. Liberalizing the abortion law and increased access to abortion providers can indeed be associated with a higher probability that women turn to induced abortion to terminate an unintended pregnancy. The Dutch abortion policies have long been and still are among the most liberal in the world; this finding does little to explain why Dutch abortion rates are so low.

Policies that were aimed at preventing unwanted pregnancies and thus reduce the demand for abortion also have been effective. Policies that allow insurance of birth control pills and stimulate its availability negatively affected the likelihood that women become pregnant, which in turn implies that they were less at risk of having an induced abortion. However, whether these policies indeed reduced the number of abortions is not clear, since the probability of experiencing a pregnancy to be unintended does not seem to be affected by these policies. Legality appears to be key: if contraceptives sales were legal, women are significantly less likely to experience a pregnancy and less likely to experience an unintended pregnancy. Although our analyses are performed on Dutch women and use retrospective data, they might prove to be applicable in 
other countries as well. Our research clearly indicates that it is possible to influence the way women make these decisions by adopting policies that affect the cost-benefit evaluations regarding their reproductive behaviour. However, research testing these hypotheses in other countries is clearly warranted and called for.

\section{Notes}

1. Detailed information about the data selection process is presented in Appendix A. Additional analyses indicate that the exclusion of women who had spent some time abroad does not affect the outcomes of hypotheses testing.

2. The independent variables in our models are not multi-collinear (diagnostics available on request). We model the macro-level effects on the likelihood of having an abortion separately in models $\mathrm{C}$ and $\mathrm{D}$ to avoid multi-collinearity.

\section{Funding}

This work was supported by the Netherlands Organization for Scientific Research [grant number 452-05-305].

\section{References}

Adserà, A. (2004). Changing fertility rates in developed countries. The impact of labor market institutions. Journal of Population Economics, 17, $17-43$.

Ahn, N. and Mira, P. (2002). A note on the changing relationship between fertility and female employment rates in developed countries. Journal of Population Economics, 15, 667-682.

Bankole, A., Singh, S. and Haas, T. (1998). Reasons why women have induced abortion: evidence from 27 countries. International Family Planning Perspectives, 24, 117-127.

Bankole, A., Singh, S. and Haas, T. (1999). Characteristics of women who obtain induced abortion: a world-wide review. International Family Planning Perspectives, 25, 68-77.

Barber, J. S., Murphy, S. A., Axinn, W. and Maples, J. (2000). Discrete-time multilevel hazard analyses. Sociological Methodology, 30, 201-235.

Beck-Domzalska, M. (2007). The Narrowing Education Gap between Women and Men. Luxemburg: Eurostat.
Becker, G. S. (1965). A theory of the allocation of time. Economic Journal, 75, 493-517.

Becker, G. S. (1976). The Economic Approach to Human Behavior. Chicago: University of Chicago Press.

Becker, G. S. (1991). A Treatise on the Family. Cambridge, MA: Harvard University Press.

Becker, G. S. and Lewis, H. G. (1973). On the interaction between the quantity and quality of children. The Journal of Political Economy, 81, S279-S288.

Beets, G. (2004). De timing van het eerste kind: een overzicht. Bevolking en Gezin, 33, 115-142.

Bernhardt, E. M. (1993). Fertility and employment. European Sociological Review, 9, 25-42.

Brewster, K. L. and Rindfuss, R. R. (2000). Fertility and women's employment in industrialized nations. Annual Review of Sociology, 26, 271-296.

Bronsema, H. and Moors, H. (1994). Dertig Jaar Pilgebruik. Demos, 10, 47-48.

Da Rocha, J. M. and Fuster, L. (2006). Why are fertility rates and female employment ratios positively correlated across OECD Countries? International Economic Review, 47, 1187-1222.

De Bruijn, J. (1979). Geschiedenis van abortus in Nederland. Een analyse van opvattingen en discussies 1600-1979. Amsterdam: Van Gennep.

De Graaf, A. (2004). Geboorteregeling in 2003. Bevolkingstrends, 52, 23-27.

De Graaf, A. (2009). Geboorteregeling in 2008. Bevolkingstrends, 57, 54-59.

De Graaf, A. and Loozen, S. (2005). Ongeplande zwangeschappen. Bevolkingstrends, 53, 30-33.

De Graaf, N. D. and Te Grotenhuis, M. (2008). Traditional Christian belief and belief in the supernatural: diverging trends in the Netherlands between 1979 and 2005? Journal for the Scientific Study of Religion, 47, 585-598.

Del Boca, D. (2002). The effect of child care and part time opportunities on participation and fertility decisions in Italy. Journal of Population Economics, 15, 549-573.

Fergusson, D. M., Boden, J. M. and Horwood, L. J. (2007). Abortion among young women and subsequent life outcomes. Perspectives on Sexual and Reproductive Health, 39, 6-12.

Gius, M. P. (2007). The impact of provider availability and legal restrictions on the demands for abortions by young women. The Social Science Quarterly, 44, 495-506.

Gober, P. (1997). The role of access in explaining state abortion rates. Social Science and Medicine, 44, 1003-1016.

Haas-Wilson, D. (1993). The economic impact of state restrictions on abortion: parental consent and 
notification laws and medicaid funding restrictions. Journal of Policy Analysis and Management, 12, 498-511.

Haas-Wilson, D. (1997). Women's reproductive choices: the impact of medicaid funding restrictions. Family Planning Perspectives, 29, 228-233.

Halman, L. C. J. M. and Draulans, V. J. R. (2006). How secular is Europe? British Journal of Sociology, 57, 263-288.

Inspectie voor de Gezondheidszorg. (nd). Administrative records of Dutch abortion clinics. Personal Communication. Den Haag: Inspectie voor de Gezondheidszorg.

Ketting, E. (1978). Van Misdrijf tot hulpverlening. Een analyse van de maatschappelijke betekenis van abortus provocatus in Nederland. Alphen aan de Rijn: Samson Uitgeverij.

Ketting, E. and Schnabel, P. (1980). Induced abortion in the Netherlands: a decade of experience, 1970-1980. Studies in Family Planning, 11, 385-394.

Ketting, E. and Visser, A. P. (1994). Contraception in the Netherlands: the low Dutch abortion rate explained. Patient Education and Counseling, 23, 161-171.

Kiernan, K. (2002). The state of European Unions: an analysis of partnership formation and dissolution. In Macura, M. and Beets, G. (Eds.), Dynamics of Fertility and Partnership in Europe: Insights and Lessons from Comparative Research. New York and Geneva: United Nations, pp. 57-76.

Kruijer, Van Lee and Wijssen, (2009). Landelijke Abortus Registratie. Utrecht: Rutgers Nisso Groep.

Levine, P. B. (2004). Sex and Consequences. Abortion, Public Policy, and the Economics of Fertility. Princeton: Princeton University Press.

Medoff, M. H. (1988). An economic analysis of the demand for abortions. Economic Inquiry, 26, 353-359.

Rademakers, J. (2002). Abortus in Nederland 19932000. Jaarverslag van de landelijke abortusregistratie. Heemstede: StiSan.

Rahmqvist, M. (2006). The close relationship between birth, abortion and employment rates in Sweden from 1980 to 2004. Social Science and Medicine, 63, 1262-1266.

Rensman, E. (2006). De Pil in Nederland. Een mentaliteitsgeschiedenis. Amsterdam: Athenaeum Polak \& Van Gennip.

Rossier, C., Michelot, F. and Bajos, N. (2007). The COCON Group (2007). Modeling the process leading to abortion: an application to french survey data. Studies in Family Planning, 38, 163-197.

Rutgers Nisso Groep (2004). Factsheet Gevolgen Pil uit het Ziekenfonds. Utrecht: Rutgers Nisso Groep.

Sedgh, G. et al. (2007). Induced abortion: estimated rates and trends worldwide. Lancet, 370, 1338-1345.

Sihvo, S. et al. (2003). Women's life cycle and abortion decision in unintended pregnancies. Journal of Epidemiology and Community Health, 57, 601-605.

Statistics Netherlands (2003). Family and Fertility Survey 2003 [Onderzoek Gezinsvorming 2003]. Data file. Voorburg/ Heerlen: Statistics Netherlands.

Statistics Netherlands (2008a). Percentage Dutch Women 16-49 using Oral Birth Control, available from: <http://statline.cbs.nl> [accessed 29 April 2008].

Statistics Netherlands (2008b). Dutch Unemployment Rates, available from: <http://statline.cbs.nl> [accessed 9 May 2008].

Statistics Netherlands (2008c). Dutch Female Labor Market Participation Rates, available from: <http:// statline.cbs.nl> [accessed 9 May 2008].

Treffers, P. E. (2006). Abortus Provocatus in Nederland in de 20e eeuw: van Stilzwijgen naar Revolutionaire Verandering. Nederlands Tijdschrift voor Geneeskunde, 150, 567-573.

Trussel, J., Menken, J., Lindheim, B. L. and Vaughan, B. (1980). The impact of restricting medicaid financing for abortion. Family Planning Perspectives, 12, 120-130.

Vos, A. E. (2009). Falling fertility rates: new challenges to the European welfare state. Socio-Economic Review, 7, 485-503.

Wijsen, C. and van Lee, L. (2006). Landelijke abortusregistratie 2005. Utrecht: Rutgers Nisso Groep.

Wijssen, C., van Lee, L. and Koolstra, H. (2007). Abortus in Nederland 2001-2005. Delft: Uitgeverij Eburon.

\section{Authors' Addresses}

Mark Levels (to whom correspondence should be addressed), Department of Sociology/ICS, Radboud University Nijmegen, P.O. Box 9104, 6500 HE Nijmegen, the Netherlands. Email: m.levels@maw.ru.nl

Ariana Need, Department of Social Risks and Safety Studies, University of Twente School of 
Management and Government, P.O. Box 217, 7500

AE Enschede, the Netherlands. Email: a.need@utwente.nl

Rense Nieuwenhuis, Department of Social Risks and Safety Studies, University of Twente School of Management and Government, P.O. Box 217, 7500 AE Enschede, the Netherlands. Email: r.r.nieuwenhuis@utwente.nl

Roderick Sluiter, Department of Sociology/ICS, Radboud University Nijmegen, P.O. Box 9104, 6500 HE Nijmegen, the Netherlands. Email: r.sluiter@maw.ru.nl

Wout Ultee, Department of Sociology/ICS, Radboud University Nijmegen, P.O. Box 9104, 6500 HE Nijmegen, the Netherlands. Email: w.ultee@maw.ru.nl

Manuscript received: January 2010

\section{Appendix A}

Raw data:

- Women reported having given birth to 6,612 biological children.

- In total, 507 women reported a total number of 619 unintended pregnancies.

- Of the 619 reported unintended pregnancies, at least 349 ended in a live birth. These pregnancies are already included in the number of children.

- At least 238 unintended pregnancies were not carried to term.

- On 32 reported unintended pregnancies, no information about the pregnancy result was known. Data contained only information about the first and second unintended pregnancy-the 32 pregnancies were the third, fourth or fifth time a woman experienced an unintended pregnancy.

- Women had had 6,612 +238=6,760 pregnancies.

After deleting non-imputable missing values on age at occurring unwanted pregnancies
- The resulting women reported 6,580 biological children, of which 347 were born after an unintended pregnancy. At least 232 unintended pregnancies were not carried to term. In total, the 4,208 women had a total number of 6,734 pregnancies.

After deleting missing values on the age of pregnancies that were carried to termThe resulting women reported 6,095 biological children, of which 325 were born after an unintended pregnancy. A total of 226 unintended pregnancies were not carried to term. In total, the 4,100 women remaining in the data set had 6,321 pregnancies.

After construction of person-period file

- When constructing the ppf, a record is created for each year in a woman's fertile life span which is (for reasons of comparability) defined as 1444-years old. Covariates may vary over time and change their value from year to year. The values time-varying covariates have are based on information about the respondent's age at occurring events.

- This led to a reduction of 45 pregnancies, 35 of which were unintended.

- In 32 cases, no information about the age of respondents at the time of occurring unintended pregnancies was known. These were all repeated unintended pregnancies. In two cases, a woman experienced two pregnancies in 1 year. One woman experienced a pregnancy in the same year she became infertile.

After deleting all records from 2003

- Ten unintended pregnancies were deleted, none of which ended in an abortion.

After deleting information about women who had spent some time abroadThis reduced the number of pregnancies we could analyse with 523 pregnancies, 69 of which were unintended. It also reduced the number of abortions with 24 . 
318 | LEVELS ET AL.

Table A1 Data Preparation and Selection

\begin{tabular}{|c|c|c|c|c|c|c|c|}
\hline & $\begin{array}{l}\text { Raw } \\
\text { data }\end{array}$ & $\begin{array}{l}\text { Missing } \\
\text { Values } \\
\text { Age ab, up }\end{array}$ & $\begin{array}{l}\text { Missing } \\
\text { Values } \\
\text { Age at } \\
\text { pregnancy }\end{array}$ & Infertile & Ppf & $<2003$ & Abroad? \\
\hline$N$ & 4,229 & 4,208 & 4,100 & 4,082 & 4,082 & 4,082 & 3,793 \\
\hline No. of records in data & 4,229 & 4,208 & 4,100 & 4,082 & 96,289 & 93,915 & 87,375 \\
\hline No. of pregnancies & 6,760 & 6,734 & 6,321 & 6,321 & 6,276 & 6,269 & 5,746 \\
\hline No. of unintended pregnancies & 619 & 611 & 582 & 582 & 547 & 537 & 468 \\
\hline No. of abortions & $119+22$ & $118+22$ & $117+21$ & $117+21$ & 136 & 136 & 112 \\
\hline
\end{tabular}

